\title{
Excellent clinical and radiological outcome following locking compression plate fixation of displaced medial clavicle fractures
}

\author{
Markus Wurm ${ }^{1}$, Sebastian Siebenlist ${ }^{2}$, Michael Zyskowski ${ }^{1}$, Patrick Pflüger ${ }^{1}$, Peter Biberthaler ${ }^{1}$, Marc Beirer ${ }^{1 \dagger}$ and \\ Chlodwig Kirchhoff ${ }^{*+}+$ (D)
}

\begin{abstract}
Background: Treatment of medial clavicle fractures is still controversially discussed in the community of upper extremity surgeons. An increasing number of symptomatic non-unions following conservative treatment of displaced fractures led to the development of various surgical approaches. Aim of this study was to evaluate the clinical and radiological outcome following operative treatment of displaced medial end clavicle fractures.

Methods: Patients who presented with a displaced fracture of the medial clavicle between September 2012 and December 2019 were retrospectively enrolled in this study. All patients were operatively treated with open reduction and internal fixation (ORIF) using an anatomically precontoured locking compression plate (LCP) originally designed for the lateral clavicle (Synthes ${ }^{\circledR}$, Umkirch, Germany). Functional outcome was recorded using the American Shoulder and Elbow Surgeons (ASES) Score, the Munich Shoulder Questionnaire (MSQ), Shoulder Pain and Disability Index (SPADI) and Constant Score.

Results: Overall 18 patients with a mean age of $54.5 \pm 23.5$ years suffering from a displaced fracture of the medial clavicle were identified. The mean follow-up was $40.9 \pm 26.2$ months. The mean ASES accounted for $88.3 \pm 20.8$ points, the mean MSQ was $83.1 \pm 21.7$ points, the mean SPADI was $85.6 \pm 22.5$ and a mean normative age- and sex-specific Constant Score of $77.5 \pm 19.1$ points resulted. No minor or major complications were observed. Radiologic fracture consolidation was achieved in all patients after a mean of 6.4 months.
\end{abstract}

Conclusion: Surgical treatment of displaced medial clavicle fractures using an anatomically precontoured locking plate originally designed for the lateral clavicle led to very good to excellent clinical and functional results.

Trial registration: No: DRKS00024813, retrospectively registered 19.03 .2021 (www.drks.de).

Keywords: Displaced, Medial, Clavicle, Fracture, LCP, ORIF

\section{Background}

The incidence of medial clavicle fractures is far less frequent compared to midshaft or lateral clavicle fractures accounting for $2-9.3 \%$ of all clavicle fractures $[2,3,23$,

\footnotetext{
*Correspondence: chlodwig.kirchhoff@mri.tum.de

${ }^{\dagger}$ Marc Beirer and Chlodwig Kirchhoff contributed equally to this work.

${ }^{1}$ Department of Trauma Surgery, Klinikum rechts der Isar, Technical University Munich, Munich, Germany

Full list of author information is available at the end of the article
}

28, 35]. High-energy trauma (i.e. car or motorcycle accidents) represent the most common injury mechanism resulting in medial clavicle fractures $[4,26,28]$. Concludingly the majority of these patients are at high risk for concomitant injuries such as chest trauma or fractures of the shoulder girdle $[3,21,23]$. In this context, Throckmorton et al. reported that $90 \%$ of the patients with medial clavicle fractures sustained multiple injuries and were considered as "multitrauma patients" [28]. original author(s) and the source, provide a link to the Creative Commons licence, and indicate if changes were made. The images or other third party material in this article are included in the article's Creative Commons licence, unless indicated otherwise in a credit line to the material. If material is not included in the article's Creative Commons licence and your intended use is not permitted by statutory regulation or exceeds the permitted use, you will need to obtain permission directly from the copyright holder. To view a copy of this licence, visit http://creativecommons.org/licenses/by/4.0/. The Creative Commons Public Domain Dedication waiver (http://creativecommons.org/publicdomain/zero/1.0/) applies to the data made available in this article, unless otherwise stated in a credit line to the data. 
The common literature reveals a large number of publications regarding the treatment of midshaft as well as lateral clavicle fractures, however, little is known about optimal treatment of medial clavicle fractures [5, 9, 22, $23,30]$. Although several classification systems have been developed to describe the fracture pattern and the degree of dislocation, subsequent treatment guidelines are still missing [21, 28, 31]. In the past, non-surgical treatment has been the treatment of choice even in displaced medial clavicle fractures due to good healing rates [23]. In contrast, surgical treatment was considered in open fractures or relevant concomitant injuries concerning the shoulder girdle as well as injuries of neurovascular structures $[4,22]$. However, symptomatic non-union leading to dysfunction occurred in $2.9-8 \%$ of the patients, therefore treatment strategy especially in physically active, but also young patients changed over the last years $[4,10,23]$. In addition, clavicle shortening following non-surgical treatment results in decreased moment generating- as well as total force generating capacity of the shoulder girdle muscles [18]. Therefore various surgical approaches using different fixation techniques (i.e. intramedullary implants, cerclage techniques, locking plate fixation) were used resulting in good to excellent results $[7,10,13,23,29$, 37].

Accordingly the aim of this study was to evaluate the clinical and radiological outcome using an anatomically precontoured locking plate originally designed for the lateral clavicle after a follow-up of at least one year.

\section{Methods}

Patients

Institutional review board approval was obtained prior to study begin by the local ethics committee. Patients who were operatively treated with an anatomically precontoured locking compression plate $\left(\right.$ Synthes ${ }^{\circledR}$, Umkirch, Germany) for displaced medial clavicle fractures at our level 1 trauma center between September 2012 and December 2019 were retrospectively identified. The plate design was originally developed for the lateral clavicle third however by rotating the LCP by $180^{\circ}$ the plate was perfectly adjusted to the medial clavicle third as depicted by our study group in 2014 [27]. All fractures were classified according to the $\mathrm{AO} /$ OTA, Edinburgh, Throckmorton\&Kuhn and vanTongel (anatomically based, AB) classification [15, 21, 28, 31] (Table 1). Preoperative radiographs were performed in 2 planes (anterior-posterior perpendicular to cassette and anterior-posterior 30 degree angle cephalad). Additional computed tomography was performed in polytraumatized patients as well as in cases when conventional radiographs were not sufficient to adequately evaluate fracture morphology. Trauma mechanism, concomitant injuries as well as surgical duration and complications were recorded.

\section{Surgical technique and rehabilitation}

The here presented surgical technique has been described by Siebenlist et al. [27]. Patients were placed in a beach-chair position with the affected arm in a

Table 1 Fracture Classification of dislocated medial end clavicle fractures. (AO/OTA [15], Edinburgh Classification [21], Throckmorton\&Kuhn Classification including Displacement (minimal $=<2 \mathrm{~mm}$, moderate 2-10 mm, severe $>10 \mathrm{~mm}$ ) [28] and anatomically based (AB) Classification [31]

\begin{tabular}{|c|c|c|c|c|c|}
\hline Patient No. & $\begin{array}{l}\text { AO / OTA } \\
\text { Classification }\end{array}$ & $\begin{array}{l}\text { Edinburgh } \\
\text { Classification }\end{array}$ & Throckmorton\&Kuhn & Displacement & $\begin{array}{l}\text { Anatomically } \\
\text { Based }\end{array}$ \\
\hline 1 & $151 . A$ & 1B1 & C & severe & $1 \mathrm{~B}$ \\
\hline 2 & $151 . \mathrm{A}$ & 1B1 & C & moderate & $1 \mathrm{~B}$ \\
\hline 3 & $151 . \mathrm{A}$ & 1B1 & A & moderate & $1 \mathrm{~B}$ \\
\hline 4 & $151 . \mathrm{A}$ & 1B1 & A & moderate & $1 \mathrm{~B}$ \\
\hline 5 & $151 . \mathrm{A}$ & 1B1 & C & severe & $1 \mathrm{~B}$ \\
\hline 6 & $151 . C$ & 1B2 & D & moderate & $1 \mathrm{~B}$ \\
\hline 7 & $151 . \mathrm{A}$ & 1B1 & $A$ & moderate & $1 \mathrm{~B}$ \\
\hline 8 & $151 . \mathrm{A}$ & 1B1 & C & moderate & $1 \mathrm{~B}$ \\
\hline 9 & $151 . \mathrm{A}$ & $1 \mathrm{~B} 1$ & A & moderate & $1 \mathrm{~B}$ \\
\hline 10 & $151 . \mathrm{A}$ & 1B1 & A & minimal & $1 \mathrm{~B}$ \\
\hline 11 & $151 . \mathrm{A}$ & 1B1 & D & severe & $1 \mathrm{~B}$ \\
\hline 12 & $151 . \mathrm{A}$ & 1B1 & C & severe & $1 \mathrm{~B}$ \\
\hline 13 & $151 . \mathrm{A}$ & 1B1 & C & severe & $1 \mathrm{~B}$ \\
\hline 14 & $15.2 \mathrm{~A}$ & 1B2 & A & moderate & $1 \mathrm{~B}$ \\
\hline 15 & $15.3 \mathrm{~A}$ & $1 \mathrm{~B} 2$ & C & moderate & $1 \mathrm{~B}$ \\
\hline
\end{tabular}


mobile position. A longitudinal skin incision was made upon the medial clavicle with extension to the sternoclavicular (SC) joint without affecting it. After sharp dissection of the periosteum and debridement, the fracture was sparingly exposed. The position was checked clinically as well as via fluoroscopy. The plate was placed onto the clavicular shaft close to the SC joint without harming it.

In cases of multiple trauma patients additional surgery was performed (1) either immediately in our emergency department, (2) during plate fixation of the medial clavicle fracture or (3) after treatment and monitoring at the intensive care unit (see Table 2).

Postoperatively, immobilization was performed in an arm-sling (MediSling, Bayreuth, Germany) and patients started routine physical therapy on the first postoperative day. Abduction and flexion were restricted to $90^{\circ}$ for the first six weeks. Return to sportive activity was allowed 6 weeks postoperatively.

\section{Follow-up}

Shoulder function and pain as well as radiographic outcome were assessed at 6,12,26 weeks and one year after surgery. Implant removal was performed in case of irritation and explicit patients' request. Functional outcome was recorded using the American Shoulder and Elbow Surgeons (ASES) Score [16] and the Munich Shoulder Questionnaire (MSQ) [24] allowing for self-assessment of the Shoulder Pain and Disability Index (SPADI) [19] and the sex and gender adapted Constant Score [6].

\section{Statistics}

Data is given in terms of the arithmetic mean \pm standard deviation. Descriptive statistics were used to illustrate the

Table 2 Concomitant injuries and additional surgical treatment ((1) immediately in our emergency department, (2) during plate fixation of the medial clavicle fracture ( $\mathrm{fx}$ ) or (3) after treatment and monitoring in the intensive care unit)

\begin{tabular}{|c|c|c|c|}
\hline Pat. No & Concomitant injury & Additional surgical treatment & $\begin{array}{l}\text { Timing } \\
\text { of } \\
\text { surgery }\end{array}$ \\
\hline 1 & - & - & - \\
\hline 2 & AC-Joint dislocation & AC-Joint stabilisation & 2 \\
\hline \multirow[t]{2}{*}{3} & \multirow[t]{2}{*}{ Humeral head fx (Neer IV.2), Subdural hemorrhage } & Locking plate fixation of the humeral head & 2 \\
\hline & & External ventricular drainage & 2 \\
\hline 4 & - & - & - \\
\hline 5 & - & - & - \\
\hline 6 & Pneumothorax, serial rib $\mathrm{fx}$, discoligamentary instability $\mathrm{C} 3 / 4$ & ACDF C $3 / 4+$ plate fixation $\mathrm{C} 3 / 4$ & 3 \\
\hline 7 & Serial rib fx, Pneumothorax & Chest tube & 1 \\
\hline 8 & - & - & - \\
\hline \multirow[t]{5}{*}{9} & Subarachnoid hemorrhage & Conservative management of SAH & 1 \\
\hline & Pneumothorax & Chest tube & 2 \\
\hline & Serial Rib fx & Locking plate fixation of the humeral head & 2 \\
\hline & Floating Shoulder (med + lat. Clavicle Fx, multifragm. Scapula Fx) & Double Plate fixation of the clavicle (LCP) & \\
\hline & prox. Humeral Fx & & \\
\hline \multirow[t]{3}{*}{10} & Basilar Skull Fx & Plate fixation scapula & 2 \\
\hline & Serial Rib Fx & & \\
\hline & Scapula Fx & & \\
\hline 11 & - & - & - \\
\hline \multirow[t]{4}{*}{12} & Traumatic brain injury $1^{\circ}$ & Chest tube & 1 \\
\hline & Serial Rib Fx & & \\
\hline & Pubic Fx & & \\
\hline & Pneumothorax & & \\
\hline \multirow[t]{4}{*}{13} & Traumatic Brain injury $1^{\circ}$ & Conservative management of SAH & 3 \\
\hline & Basilar Skull Fx & Ankle: Plate / Screw osteosynthesis & \\
\hline & Subarachnoid Hemorrhage & & \\
\hline & Trimalleolar Ankle Fx & & \\
\hline 14 & - & - & - \\
\hline 15 & - & - & - \\
\hline
\end{tabular}


results. Statistical evaluation was performed using SPSS 25.0 (IBM Corp. Released 2017. IBM SPSS Statistics for Windows, Version 25.0. Armonk, NY: IBM Corp.).

\section{Results}

Between September 2012 and December 201918 patients with a mean age of $54.5 \pm 23.5$ years were operatively treated for a displaced medial clavicle fracture using an anatomically precontoured locking compression plate (Fig. 1). One patient declined to participate in this study. Two patients moved so that follow up examinations were not performed. These three patients were excluded from this study. Overall 15 patients ( 12 male, 3 female) with a mean age of $50.5 \pm 24.4$ years were available for all postoperative follow ups and thus participated in this study. Mean follow up was $40.9 \pm 26.2$ months with a minimum follow up of 12 months (range 12.6 - 83.2 months). Concomitant injuries were found in $8 / 15$ patients (53.3\%; see Table 2). Surgical treatment for concomitant injuries was necessary in $7 / 15$ patients $(46.6 \%)$. Thoracic injuries (i.e. pneumothorax) were treated immediately in our emergency department. Injuries of the ipsilateral upper extremity (proximal humerus fracture $(n=2,13.3 \%)$, ACjoint dislocation $(n=1,6,6 \%))$, scapular fracture $(n=1$, $6,6 \%)$ were surgically treated in the same session $(n=4$, $26.6 \%$ ) as the medial clavicle fracture (Table 2). The functional outcome of these 4 patients was excluded to avoid misinterpretation of a multiple injured upper extremity. Exclusion of these 4 patients did not statistical significant alter the overall functional outcome $(p=.806)$. Surgical treatment of a vertebral body fracture (cervical spine) was performed with a certain delay after surgery of the medial clavicle fracture $(n=1,6.6 \%)$. Non-surgical, conservative treatment was performed in patients suffering from concomitant injuries such as rib fractures $(n=5)$ and one non-displaced pubic fracture $(\mathrm{n}=1)$.
Neither minor (wound-healing disorders etc.) nor major (non-union, re-fracture, revision etc.) complications were observed during follow-up examinations in our outpatient clinic for medial clavicle fractures. Overall 7 implant removals were performed due to irritation and patients' request after a mean of $22.2 \pm 8.0$ months. No re-fractures were observed until last follow up examination. Bone healing was found on conventional radiographs performed at the follow-up examinations in all patients after a mean of $6.4 \pm 3.9$ months.

The mean ASES accounted for $88.3 \pm 20.8$ points, the mean normative age- and sex-specific Constant Score was $77.5 \pm 19.1$ points, the mean SPADI $85.6 \pm 22.5$ and the mean MSQ resulted in $83.1 \pm 21.7$ points. 6 patients returned to their preoperative activity / sports level with only minor restrictions in overhead activities, 9 patients did not perform any sports prior to surgery. All preoperative sportive activities could be carried out postoperative. Overall mean time for return to sports for riding bicycle, fitness, jogging, soccer and snowboarding was $8.4 \pm 3.4$ months.

\section{Discussion}

Operative treatment of medial clavicle fractures utilizing a $180^{\circ}$ twisted locking compression plate (invented for the lateral clavicle) leads to good to excellent results. Not only the degree of dislocation but also patients' activity level are important factors for decision making whether to operate or treat the fracture conservatively. The incidence of medial clavicle fractures is rather low especially when compared to midshaft or lateral clavicle fractures accounting for 2-9.3\% of all clavicle fractures [2, 3, 23, 28, $35]$. Therefore we reached out to address this rare entity and elucidate findings including concomitant injuries and present results to our operative techniques as described by Siebenlist et al. [27].

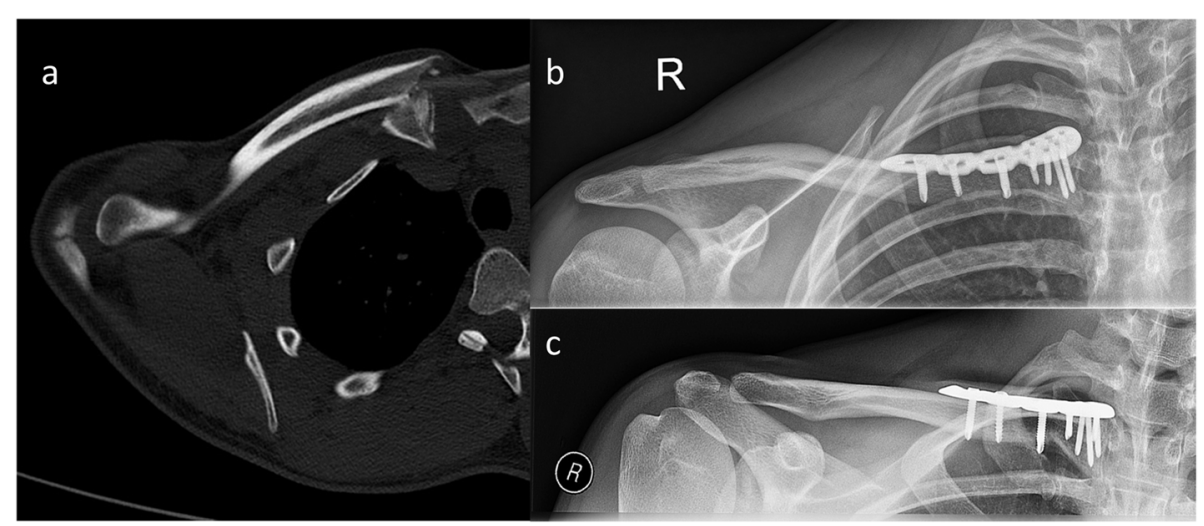

Fig. 1 a Axial Computed tomography (CT) image of a medial end clavicle fracture preoperatively. $\mathbf{b}$ and $\mathbf{c}$ present x-rays in two planes after surgical fixation of the fracture using an anatomically preformed locking compression plate (LCP, Synthes, Umkirch, Germany) 
Treatment of medial clavicle fractures is still challenging and controversially discussed in the upper extremity community. A certain consensus exists for treating non-displaced fractures conservatively. In this context several authors prefer open reduction and internal fixation of displaced fractures in physically active patients [7, $12,29]$. The use of an anatomically precontoured locking plate showed promising functional results in small case studies [7, 27, 34].

Current classification systems allow for a description of fracture pattern and degree of dislocation of medial clavicle fracture, however distinct treatment guidelines are still missing. Therefore van Tongel et al. developed an anatomically based classification system focusing on the fracture dislocation (bony vs no bony contact of fragments) and the location of the fracture line in relation to the costo-clavicular ligament and the SC joint capsule [31]. A worse functional outcome (Constant Score 70 points, SD 14) and a higher incidence of symptomatic non-unions (4/13) following nonoperative treatment was associated with a lack of bony contact in fractures medial of the costoclavicular ligament (Typ 1B) compared to fractures with bony contact of the fragments (Typ 1A, Constant Score 79 points, SD 14; no non-union). In the current study all fractures were classified as Typ $1 \mathrm{~B}$ according to van Tongel et al. [31]. Surgical treatment resulted in a considerable higher Constant Score of $77.6 \pm 17.4$ points and bony union in all cases compared to the study group of van Tongel et al. Therefore our results, in accordance with those of van Tongel et al., state the prognostic outcome for conservative treatment of Typ 1B fractures inferior. Therefore primary operative treatment should be recommended in physically active patients.

The presented study presents a retrospective trial on the clinical as well as radiological results of 15 patients suffering from dislocated fractures of the medial clavicle treated with the just mentioned anatomically precontoured locking plate originally designed for lateral clavicle fractures. The mean age of the enrolled 15 patients was $50.5 \pm 24.4$ years with a male-female ratio of $12: 3$. Unfortunately, the small cohort size is a well-known problem in outcome evaluation studies of pathologies with a low incidence such as medial clavicle fractures. Therefore, the strength of the obtained results can only considered as the fundament as well as good starting point for further analysis. However, in this context the recent literature also only provides studies enrolling little patient numbers or even lower compared to the presented study. Therefore we contribute to the poor data situation in the recent literature of this low-incidence-disease with a study of a comparatively high number of patients addressing concomitant injuries including all current classification systems.

Various surgical techniques and different implants have been in use for open reduction and internal fixation of medial end clavicle fractures [1]. None of the available implants has been especially developed for the anatomy of the medial clavicle and a standardized surgical approach has not yet been established. Due to the short metaphyseal fracture fragment, $\mathrm{Li}$ et al. suggested to use a reconstruction plate as a bridging plate technique across the sternum to the contralateral healthy clavicle in terms of a temporary arthrodesis [11]. The authors further report bony union and good clinical outcome with high satisfaction 6 months postoperatively (DASH 23.33). However, for this across-sternum technique two incisions with related crucial soft tissue trauma are necessary and both non-affected SC joints are impaired so that implant removal is mandatory. However, this is a newly described technique (case report) and long term follow up is missing why general conclusions should be omitted. An alternative to gain sufficient fixation of small metaphyseal fragments as a common problem also in fractures of the lateral clavicle could be achieved by the use of locking compression plates. Depending on the type of implant the lateral extension allows for the placement of $2.3-2.7 \mathrm{~mm}$ divergent locking screws increasing "pullout" - strength.

To avoid bending of locking plates resulting in decreased stability, anatomically precontoured locking plates were developed for numerous locations of the human skeleton presenting with a high incidence of injuries. However, the clavicle presents with a large anatomic variability in its sigmoid shape. Vancleef et al. calculated a statistical shape model of the clavicle reported data on the average clavicular geometry [32]. The authors concluded that several plate shapes are needed to fit all types of clavicle fractures.

Previously, Titchener et al. used a precontoured locking plate originally designed for the lateral clavicle for fixation of medial clavicle fractures [29]. In all cases the plate was helical bended in a $90^{\circ}$ fashion around its axis to fit to the medial clavicle. All fractures healed properly and no implant failure was reported. However, bending of locking plates can reduce the stiffness of the implant with an increased risk of implant failure [14, 20].

In contrast to Titchener et al., as reported, the lateral LCP perfectly matches the anatomy of the medial clavicle without additional bending needed. Frima et al. reported on using a VA (various angle)-LCP (distal humerus) with additional lateral support as "well-fitting" with excellent functional outcome which is in accordance to our findings $[7,12,27]$. 
Hardware removal due to soft tissue irritation is a common problem in plate fixation of clavicle fractures and was performed in $7 / 15$ cases in the presented study. These results are comparable to the results of Frima et al. in 2018 [7]. Routine removal of implants remains controversially discussed with a lack of evidence based guidelines. In a recent study our study group reported on improved functional outcome and increased activity levels after implant removal $[17,36]$. However, until now, the german-speaking society of Traumatology (DGU) appreciates implant removal as no mandatory procedure [25]. Due to typical surgical risks and complications, implant removal should only be performed in symptomatic patients (i.e. wearing heavy bags or due to weather changes) [33]. Removal of implants is most commonly performed in the clavicle. Various reason have been identified (i.e. irritation, pain etc). Due to a prominent subcutaneous position of the implant especially in patients with poor soft tissue coverage irritation rates in this area are higher compared to other regions [8]. In this context Titchener et al. positioned in all 8 enrolled patients the plate over the anterior surface of the medial clavicle and superior on the shaft so that no implant removal was necessary. However, two patients of his patients' cohort reported a slight prominent feeling of the plate [29].

\section{Limitations}

There are several limitations to be considered when interpreting the presented results. First, the retrospective character of the data analysis of our in-house fracture register may be inaccurate and may not provide the quality of a prospective data selection. Secondly, we did not compare conservatively treated patients to operatively treated ones yet with respect to degree of fracture dislocation this comparison would not have been appropriate. Future investigations with prospective randomized comparisons of operative treatment in medial end clavicle fractures need to be performed and is focus of ongoing research of our study group.

\section{Conclusion}

Locking compression plate fixation (originally developed for the lateral clavicle) of displaced medial end clavicle fractures provides decent stability due to diverging screws in the medial fracture portion in physically active patients including a very good to excellent functional outcome.

\footnotetext{
Abbreviations

AO : OTA; : Arbeitsgemeinschaft für Osteosynthesefragen; : Orthopaedic Trauma Association; DASH: Disability of Arm, Shoulder and Hand; DGU: Deutsche Gesellschaft für Unfallchirurgie; LCP: Locking compression plate; MSQ: Munich Shoulder Questionnaire; ORIF: Open reduction - internal fixation; SPADI: Shoulder Pain and Disability Index.
}

\section{Acknowledgments}

Not applicable.

\section{Authors' contributions}

M.W. and C.K. were substantially involved in conception and design of the study. P.B, C.K. and M.B. analyzed radiographs. M.W. and C.K. drafted the manuscript. M.Z., S.S., P.P. and M.B. assisted in the literature research and helped to draft the manuscript. M.W. and C.K. performed the statistical analysis. P.B., M.B., S.S. and C.K. participated in the design of the study, helped to draft the manuscript and noted critical revisions of the manuscript for important intellectual content. All authors have read and agreed to the published version of the manuscript.

\section{Authors' information}

Not applicable.

\section{Funding}

Open Access funding enabled and organized by Projekt DEAL.

\section{Availability of data and materials}

The datasets used and analyzed during the current study are available from the corresponding author on reasonable request.

\section{Declarations}

Ethics approval and consent to participate

Institutional Review Board (IRB) approval was obtained prior to this study (Ethical Committee Technical University Munich, No: 280/19S). The study was performed in accordance with the Declaration of Helsinki. All patients signed a consent to participate with respect to this study.

\section{Consent for publication}

Not applicable.

\section{Competing interests}

M. W., S. S., M. Z., P. P., P., B., M.B. and C.K. declare no conflict of interest with respect to the nature of this study. S.S. is consultant for Arthrex GmbH, Martin $\mathrm{GmbH} \&$ Co. KG and Medartis AG. P. B. is OR instructor for DepuySynthes, Zimmer, Smith\&Nephew, Arthrex, Medartis and Bonesupport. C. K. is consultant for Arthrex.

\section{Author details}

${ }^{1}$ Department of Trauma Surgery, Klinikum rechts der Isar, Technical University Munich, Munich, Germany. ${ }^{2}$ Department of Orthopaedic Sports Medicine, Klinikum rechts der Isar, Technical University Munich, Munich, Germany.

Received: 22 March 2021 Accepted: 10 October 2021

Published online: 27 October 2021

\section{References}

1. Asadollahi S, Bucknill A. Acute medial clavicle fracture in adults: a systematic review of demographics, clinical features and treatment outcomes in 220 patients. J Orthop Traumatol. 2019;20:24.

2. Bakir MS, Merschin D, Unterkofler J, et al. Injuries of the medial clavicle: a cohort analysis in a level-I-trauma-center. Concomitant injuries. Management. Classification. Chirurgia (Bucur). 2017;112:594.

3. Bakir MS, Unterkofler J, Honning A, et al. Shoulder girdle injuries involving the medial clavicle differ from lateral clavicle injuries with a focus on concomitant injuries and management strategies: a retrospective study based on nationwide routine data. PLoS One. 2019;14:e0224370.

4. Bartonicek J, Fric V, Pacovsky V. Displaced fractures of the medial end of the clavicle: report of five cases. J Orthop Trauma. 2010;24:e31-5.

5. Chen W, Zhu Y, Liu S, et al. Demographic and socioeconomic factors influencing the incidence of clavicle fractures, a national population-based survey of five hundred and twelve thousand, one hundred and eighty seven individuals. Int Orthop. 2018;42:651-8. 
6. Constant CR, Murley AH. A clinical method of functional assessment of the shoulder. Clin Orthop Relat Res. 1987:160-4.

7. Frima H, Houwert RM, Sommer C. Displaced medial clavicle fractures: operative treatment with locking compression plate fixation. Eur J Trauma Emerg Surg. 2018.

8. Hulsmans MH, Van Heijl M, Houwert RM, et al. High irritation and removal rates after plate or nail fixation in patients with displaced Midshaft clavicle fractures. Clin Orthop Relat Res. 2017;475:532-9.

9. Kihlstrom C, Moller M, Lonn K, et al. Clavicle fractures: epidemiology, classification and treatment of 2422 fractures in the Swedish fracture register; an observational study. BMC Musculoskelet Disord. 2017;18:82.

10. Kim KC, Shin HD, Cha SM. Surgical treatment of displaced medial clavicle fractures using a small T-shaped plate and tension band sutures. Arch Orthop Trauma Surg. 2011;131:1673-6.

11. Li Z, Liu H, Chen D, et al. A new technique for medial-end comminuted clavicle fractures. Injury. 2019;50:811-3.

12. Liu Z, Zhang J, Tian X, et al. Displaced medial-end clavicle fractures treated with locking plate Osteosynthesis. Med Sci Monit. 2019;25:7591-6

13. Low AK, Duckworth DG, Bokor DJ. Operative outcome of displaced medial-end clavicle fractures in adults. J Shoulder Elb Surg. 2008;17:751-4.

14. Meeuwis MA, Pull Ter Gunne AF, Verhofstad MH, et al. Construct failure after open reduction and plate fixation of displaced midshaft clavicular fractures. Injury. 2017:48:715-9.

15. Meinberg EG, Agel J, Roberts CS, et al. Fracture and dislocation classification Compendium-2018. J Orthop Trauma. 2018:32(Suppl 1):S1-S170.

16. Michener LA, Mcclure PW, Sennett BJ. American shoulder and elbow surgeons standardized shoulder assessment form, patient self-report section: reliability, validity, and responsiveness. J Shoulder Elb Surg. 2002:11:587-94.

17. Minkowitz RB, Bhadsavle $S$, Walsh M, et al. Removal of painful orthopaedic implants after fracture union. J Bone Joint Surg Am. 2007:89:1906-12.

18. Patel B, Gustafson PA, Jastifer J (2012) The effect of clavicle malunion on shoulder biomechanics; a computational study. Clin Biomech (Bristol, Avon) 27:436-442.

19. Roach KE, Budiman-Mak E, Songsiridej N, et al. Development of a shoulder pain and disability index. Arthritis Care Res. 1991;4:143-9.

20. Robertson C, Celestre P, Mahar A, et al. Reconstruction plates for stabilization of mid-shaft clavicle fractures: differences between nonlocked and locked plates in two different positions. J Shoulder Elb Surg. 2009;18:204-9.

21. Robinson CM. Fractures of the clavicle in the adult. Epidemiology and classification. J Bone Joint Surg Br. 1998:80:476-84.

22. Ropars M, Thomazeau H, Huten D. Clavicle fractures. Orthop Traumatol Surg Res. 2017;103:S53-9.
23. Salipas A, Kimmel LA, Edwards ER, et al. Natural history of medial clavicle fractures. Injury. 2016:47:2235-9.

24. Schmidutz F, Beirer M, Braunstein V, et al. The Munich shoulder questionnaire (MSQ): development and validation of an effective patient-reported tool for outcome measurement and patient safety in shoulder surgery. Patient Saf Surg. 2012;6:9.

25. Sehmisch S, Müller-Färber J. Implantatentfernung nach Osteosynthese. AWMF Online Nr. 2018:012-04.

26. Sidhu VS, Hermans D, Duckworth DG. The operative outcomes of displaced medial-end clavicle fractures. J Shoulder Elb Surg. 2015:24:1728-34

27. Siebenlist S, Sandmann G, Kirchhoff C, et al. Anatomically precontoured LCP for delayed union of a medial third clavicle fracture. Case report with review of the literature. Acta Chir Orthop Traumatol Cechoslov. 2013;80:407-10.

28. Throckmorton T, Kuhn JE. Fractures of the medial end of the clavicle. J Shoulder Elb Surg. 2007;16:49-54.

29. Titchener A, See A, Van Rensburg L, et al. Displaced medial end clavicular fractures treated with an inverted distal clavicle plate contoured through 90 degrees. J Shoulder Elb Surg. 2018.

30. Van Der Meijden OA, Gaskill TR, Millett PJ. Treatment of clavicle fractures: current concepts review. J Shoulder Elb Surg. 2012;21:423-9.

31. Van Tongel A, Toussaint A, Herregods $S$, et al. Anatomically based classification of medial clavicle fractures. Acta Orthop Belg. 2018;84:62-7.

32. Vancleef $\mathrm{S}$, Herteleer $\mathrm{M}$, Carette $\mathrm{Y}$, et al. Why off-the-shelf clavicle plates rarely fit: anatomic analysis of the clavicle through statistical shape modeling. J Shoulder Elb Surg. 2019;28:631-8.

33. Wang J, Chidambaram R, Mok D. Is removal of clavicle plate after fracture union necessary? Int J Shoulder Surg. 2011:5:85-9.

34. Wang Y, Jiang J, Dou B, et al. Inverted distal clavicle anatomic locking plate for displaced medial clavicle fracture. Arch Orthop Trauma Surg. 2015;135:1241-5

35. Wurm M, Beirer M, Biberthaler P, et al. Clavicular fractures : diagnostics, management and treatment. Unfallchirurg. 2018;121:983-98.

36. Wurm M, Beirer M, Zyskowski M, et al. Does implant removal of superior clavicle plate osteosynthesis affect the functional outcome: a prospective trial. Arch Orthop Trauma Surg. 2020

37. Zlowodzki M, Zelle BA, Cole PA, et al. Treatment of acute midshaft clavicle fractures: systematic review of 2144 fractures: on behalf of the evidence-based Orthopaedic trauma working group. J Orthop Trauma. 2005;19:504-7.

\section{Publisher's Note}

Springer Nature remains neutral with regard to jurisdictional claims in published maps and institutional affiliations.
Ready to submit your research? Choose BMC and benefit from:

- fast, convenient online submission

- thorough peer review by experienced researchers in your field

- rapid publication on acceptance

- support for research data, including large and complex data types

- gold Open Access which fosters wider collaboration and increased citations

- maximum visibility for your research: over 100M website views per year

At BMC, research is always in progress.

Learn more biomedcentral.com/submissions 